\title{
miR-449 overexpression inhibits papillary thyroid carcinoma cell growth by targeting RET kinase- $\beta$-catenin signaling pathway
}

\author{
ZONGYU LI $^{1 *}$, XIN HUANG ${ }^{2 *}$, JINKAI XU $^{1}$, QINGHUA SU $^{1}$, JUN ZHAO $^{1}$ and JIANCANG MA ${ }^{1}$ \\ ${ }^{1}$ Department of General Surgery, The Second Affiliated Hospital of Xi'an Jiaotong University; \\ ${ }^{2}$ Department of General Surgery, The Xi'an Central Hospital of Xi'an Jiaotong University, Xi'an, Shaanxi 710004, P.R. China
}

Received May 20, 2016; Accepted July 13, 2016

DOI: 10.3892/ijo.2016.3659

\begin{abstract}
Papillary thyroid carcinoma (PTC) is the most common thyroid cancer and represent approximately $80 \%$ of all thyroid cancers. The present study is aimed to investigate the role of microRNA (miR)-449 in the progression of PTC. Our results revealed that miR-449 was underexpressed in the collected PTC specimens compared with non-cancerous PTC tissues. Overexpression of miR-449 induced a cell cycle arrest at G0/G1 phase and inhibited PTC cell growth in vitro. Further studies revealed that RET proto-oncogene (RET) is a novel miR-449 target, due to miR-449 bound directly to its 3'-untranslated region and miR-449 mimic reduced the protein expression of RET. Similar to the effects of miR-449 overexpression, RET downregulation inhibited cell growth, whereas RET overexpression reversed the inhibitive effect of miR-449 mimic. Furthermore, miR-449 overexpression inhibited the nuclear translocation of $\beta$-catenin and reduced the expression of several downstream genes, including c-Myc, cyclin D1, T cell-specific transcription factor (TCF) and lymphoid enhancer-binding factor 1 (LEF-1), and inactivated the $\beta$-catenin pathway in TPC-1 cells. Moreover, overexpression of $\beta$-catenin prevented miR-449-reduced cell cycle arrest and cell viability. In xenograft animal experiments, miR-449 overexpression effectively suppressed the tumor growth of PTC. Taken together, our research indicated that miR-449 functions as an anti-oncogene by targeting RET, and that
\end{abstract}

Correspondence to: Dr Jiancang Ma, Department of General Surgery, The Second Affiliated Hospital of Xi'an Jiaotong University, Xi'an, Shaanxi 710004, P.R. China

E-mail: jiancang_ma@163.com

*Contributed equally

Abbreviations: PTC, papillary thyroid carcinoma; miR, microRNA; RET, RET proto-oncogene; PCNA, proliferating cell nuclear antigen; TCF, T cell-specific transcription factor; LEF-1, lymphoid enhancer-binding factor 1

Key words: papillary thyroid carcinoma, microRNA-449, RET proto-oncogene, $\beta$-catenin
miR-449 overexpression inhibited the growth of PTC by inactivating the $\beta$-catenin pathway. Thus, miR-449 may serve as a potential therapeutic strategy for the treatment of PTC.

\section{Introduction}

Thyroid cancer is the leading cause of increased morbidity and mortality for endocrine malignancies, and papillary thyroid carcinoma (PTC) accounts for $80 \%$ of thyroid cancer cases (1). Reports have indicated that PTC have a homogeneous molecular signature during tumorigenesis compared with other human cancers, with wide variability in clinical behaviors (2). Due to the refractory nature of PTC to conventional radiation and drug treatment, a subset of PTC is clinically aggressive and fatal (3). However, the current prognostic factors are not fully able to provide the molecular information that is potentially useful for the prognostic evaluation and treatment of PTC (4).

The mammalian genome contains several hundred microRNAs (miRNAs), which are non-coding RNAs, 18-25 nucleotides (nt) in length, that regulate the expression of $30 \%$ of human genes (5). miRNAs can suppress the expression of oncogenes, thus serving as tumor suppressors. Also, they can promote the progression of neoplasms by reducing the expression of some tumor suppressors (6). The deregulation of miRNAs has been evidenced in a broad spectrum of diseases, including all major cancers (7). However, only a few human miRNAs have been shown to be dysregulated in PTC, including miR-449 (8), miR-129-5p (9) and miR-146-5p (10). Accumulated reports indicate that miR-449 serves as a tumor suppressor by inducing senescence and apoptosis (11). However, to our knowledge, no functional evidence of miR-449 in PTC has been documented.

The RET proto-oncogene (RET) is a transmembrane receptor-type tyrosine kinase. Under normal cellular conditions, RET is activated by binding of both glial cell line-derived neurotrophic factor (GDNF) ligands and cell surface-bound co-receptors of the GDNF family receptor a (GFRa) proteins (12). The RET receptor tyrosine kinase has essential roles in cell survival, differentiation and proliferation (13). Oncogenic activation of RET causes the cancer syndrome multiple endocrine neoplasia type 2 (MEN2) and is a frequent event in sporadic thyroid carcinomas (14). RET activation has been reported to stimulate RAS-ERK, c-Jun-NH2-kinase, phosphoinositide 3-kinase, p38 mitogen-activated protein 
kinase (MAPK) and signal transducer and activator of transcription (STAT) (15). However, the identity of the critical secondary oncogenic signals involved in the progression of RET-mediated PTC is still largely unknown.

$\beta$-catenin is a key downstream transcriptional activator of the Wnt signaling pathway. Under normal conditions, cytoplasmic $\beta$-catenin is constantly degraded by a destruction complex. However, the activation of Wnt signaling disrupts this complex, enables $\beta$-catenin stabilization and cytoplasmic accumulation, and finally translocation to the nucleus (16). Once inside the nucleus, $\beta$-catenin interacts with the transcription factor lymphoid enhancer-binding factor 1 (LEF)/T cell-specific transcription factor (TCF) to upregulate the expression of genes involved in cell migration, growth, differentiation and survival (17). Loss of membrane-associated $\beta$-catenin, often with an accompanying relative increase in cytosolic or nuclear expression, has been noted in anaplastic and poorly differentiated thyroid carcinomas and in thyroid papillary microcarcinoma (18). Reports have indicated that the $\beta$-catenin-RET kinase pathway is a critical contributor to the development and metastasis of human thyroid carcinoma (19). Thus, inhibiting the RET-involved $\beta$-catenin pathway may hinder PTC progression.

The present study investigated the potential involvement of miR-449 in PTC. We hypothesized that miR-449 could inhibit tumor growth of PTC by targeting RET expression and inactivating $\beta$-catenin signaling. Our results suggest that miR-449 may provide a better understanding of the process of PTC.

\section{Materials and methods}

TPC sample. Twenty-five pairs of human PTC and adjacent normal tissues were obtained from the Second Affiliated Hospital of Xi'an Jiaotong University (Shaanxi, China). The tissues were frozen in liquid nitrogen and stored at $-80^{\circ} \mathrm{C}$ until use. Written informed consent for tissue donation (for research purposes) was obtained from the patients, and the protocol was approved by the Institutional Review Board of the Second Affiliated Hospital of Xi'an Jiaotong University.

Cell lines. Four human PTC cell lines, including TPC-1, K1, IHH-4 and CGTH-W3, were obtained from the American Type Culture Collection (ATCC; Manassas, VA, USA). The human thyroid epithelial cell lines Nthy-ori3-1 and HTori-3 were purchased from Shanghai Cell Collection (SCC; Shanghai, China). These cell lines were cultured in Dulbecco's modified Eagle's medium (DMEM) plus 10\% fetal bovine serum (FBS; Life Technologies, Inc., Grand Island, NY, USA) at $37^{\circ} \mathrm{C}$ in a humidified atmosphere containing $5 \% \mathrm{CO}_{2}$.

Quantitative real-time polymerase chain reaction ( $q R T-P C R$ ). The total RNA was extracted from TRIzol reagent (Invitrogen, Carlsbad, CA, USA) following the manufacturer's instructions. The RT-PCR primers for miR-449 and U6 were purchased from GeneCopoeia (San Diego, CA, USA). The PCR primers for RET were: 5'-AATTTGGAAAAGTGGTCAAGGC-3' (sense) and 5'-CTGCAGGCCCCATACAAT-3' (antisense) (186 bp). To analyze the gene expression, the qRT-PCR mixture system containing the cDNA templates, primers and
SYBR-Green qPCR Master Mix was subjected to qRT-PCR quantification according to the standard methods. $\beta$-actin and U6 snRNA were used as the internal control of the mRNA or miRNA, respectively. Relative gene expression was quantified by the $2^{-\Delta \Delta \mathrm{Ct}}$ method.

Northern blot analysis. miR-449 expression levels in PTC samples, adjacent normal tissues, PTC cell lines, and human thyroid epithelial cell lines were further determined by Northern blot assay. Northern blot analysis was performed according to previously described procedures (20).

Cell cycle analysis and cell proliferation assay. Cells $\left(5 \times 10^{3}\right)$ were plated into each well of 96-well plates. Six hours later, the cells were treated with miR-control or miR-449 mimic. The procedures of cell cycle analysis were previously described (21). At 24, 48, 72, 96 and $120 \mathrm{~h}$, cell numbers were determined by Scepter ${ }^{\mathrm{TM}} 2.0$ handheld automated cell counter.

Western blotting. Whole cells were lysed in lysis buffer (Beyotime Institute of Biotechnology, Haimen, China) supplemented with $1 \mathrm{mM}$ phenylmethanesulfonyl fluoride (PMSF). The protein concentration was determined using the BCA protein assay (Tiangen Biotech, Co., Ltd., Beijing, China). Twenty micrograms of protein in each sample was separated by $12 \%$ SDS-PAGE and electrotransferred to polyvinylidene dluoride (PVDF) membranes (Millipore, Billerica MA, USA) for immunoblotting. The following primary antibodies were used: anti-RET (1:1,000, ab134100; Abcam, Shanghai, China), anti-Ki-67 (1:1000, ab15580; Abcam), anti-proliferating cell nuclear antigen (PCNA) (1:500, ab18197; Abcam), anti$\beta$-catenin (1:4000, ab16051; Abcam) and anti-GAPDH (1:2500, ab9485; Abcam), which was used as the internal reference. After incubation with the appropriate horseradish peroxidase (HRP)-conjugated secondary antibody, proteins were detected using a ChemiDoc XRS imaging system and Quantity One analysis software (Bio-Rad Laboratories, San Francisco, CA, USA).

Luciferase reporter assay. The cDNA of RET was amplified by PCR, and general method of recombinant DNA was used to clone the wild-type (WT) 3'-UTR and mutant (MUT) 3'-UTR of RET. The WT and MUT sequences of RET were then cloned into a pMIR-REPORT luciferase reporter vector (Ambion, Austin, TX, USA) to generate constructs of Luc-RET and Luc-RET-mut, followed by DNA sequencing verification. The pMIR-REPORT control vector (Luc-control) was also cloned. All three vectors were transfected into TPC-1cells/IHH-4 cells in 6-well plates with a Lipofectamine 2000 reagent kit (Sigma-Aldrich, St. Louis, MO, USA). After 1 day, the luciferase activity was measured using a luciferase reporter assay system (Promega, Madison, WI, USA). All relative luciferase activities were normalized to the condition of Luc-control with $\beta$-galactosidase transfection.

siRNA transfection. The small interfering RNA (siRNA), to genetically downregulate RET (RET-siRNA), as well as its non-specific scramble siRNA (NC-siRNA), were purchased from Guangzhou RiboBio Co., Ltd. (Guangzhou, China). Transfection of siRNAs into TPC-1 cells was conducted using 
Lipofectamine 2000 reagent kit. In TPC-1 cells, $100 \mathrm{nM}$ siRNAs (RET-siRNA and NC-siRNA) were used. The efficiency of siRNA knockdown was confirmed by western blot analysis $48 \mathrm{~h}$ after transfection.

RET and $\beta$-catenin overexpression. RET and $\beta$-catenin overexpression was achieved by PCR amplification using their cDNA as templates, separately, and the RET and $\beta$-catenin expressing vectors were constructed by inserting their cDNA into pcDNA 3.1 vector. The recombinant plasmids and other agents were co-transfected into $3 \times 10^{6}$ TPC- 1 cells using a nucleofector instrument. Forty-eight hours later, subsequent experiments were performed on the cells. The experiment was replicated thrice for data calculations.

Immunofluorescence staining. Fluorescent cells were cultured on 8-well chamber CultureSlides (Becton Dickinson, Bedford, MA, USA). After $8 \mathrm{~h}$, cells were fixed in 3\% paraformaldehyde in PBS at room temperature for $8 \mathrm{~min}$, then permeabilized with $0.2 \%$ Triton X-100 for $15 \mathrm{~min}$ at room temperature. After washing in PBS, the cells were incubated with primary mouse anti- $\beta$-catenin monoclonal antibody $(1 \mathrm{mg} / \mathrm{ml}$; Transduction Laboratories, Lexington, KY, USA) at $4^{\circ} \mathrm{C}$ overnight. After washing, cells were incubated with biotinylated goat antimouse IgG (Pierce, Rockford, IL, USA) at room temperature for $1 \mathrm{~h}$. The immunoreactivity was revealed using Alexa568conjugated streptavidin (Molecular Probes, Eugene, OR, USA), and cells were counterstained with $10 \mathrm{mg} / \mathrm{ml}$ DAPI. The cells were examined under a Nikon fluorescence microscope (Image Systems, Columbia, MD, USA).

TOP-FLASH/FOP-FLASH luciferase reporter assay. The assay was conducted according to a previous report (22), where each well was incubated with a mixture containing $20 \mu \mathrm{l}$ of serum-free DMEM, $0.6 \mu \mathrm{l}$ of FuGENE, $0.15 \mu \mathrm{g}$ of the firefly luciferase reporter plasmid, $0.15 \mu \mathrm{g}$ of the $\beta$-catenin expression vector, $0.15 \mu \mathrm{g}$ of the TCF- 4 expression vector, and $0.8 \mathrm{ng}$ of the Renilla luciferase vector phRG-TK. Then, $24 \mathrm{~h}$ after transfection, the cells were lysed in $50 \mu$ l of passive lysis buffer, and the luciferase activity was determined with a luminometer using the Dual-Luciferase assay aystem (Promega) on $20 \mu \mathrm{l}$ of lysate. Results were expressed as fold induction. Fold induction was determined by normalizing each firefly luciferase value to the Renilla luciferase internal control value and by dividing these normalized values with the mean normalized value of the corresponding reporter construct transfected with the empty expression vectors.

PTC xenografts. Male athymic nude mice were housed and manipulated according to the protocols approved by the Experimental Animal Center of the Second Affiliated Hospital of Xi'an Jiaotong University. For each mouse, $5 \times 10^{6}$ miR-449-overexpressing TPC-1 cells were injected subcutaneously into the right scapula in 100 serum-free medium. After the development of a palpable tumor, the tumor volume was monitored every 5 days and assessed by measuring the 2 perpendicular dimensions using a caliper and the formula $\left(\mathrm{a}_{\mathrm{x}} \mathrm{b}^{2}\right) / 2$, where $\mathrm{a}$ is the larger and $\mathrm{b}$ is the smaller dimension of the tumor. At 25 days after the inoculation, the mice were sacrificed and tumor weights were assessed. A portion
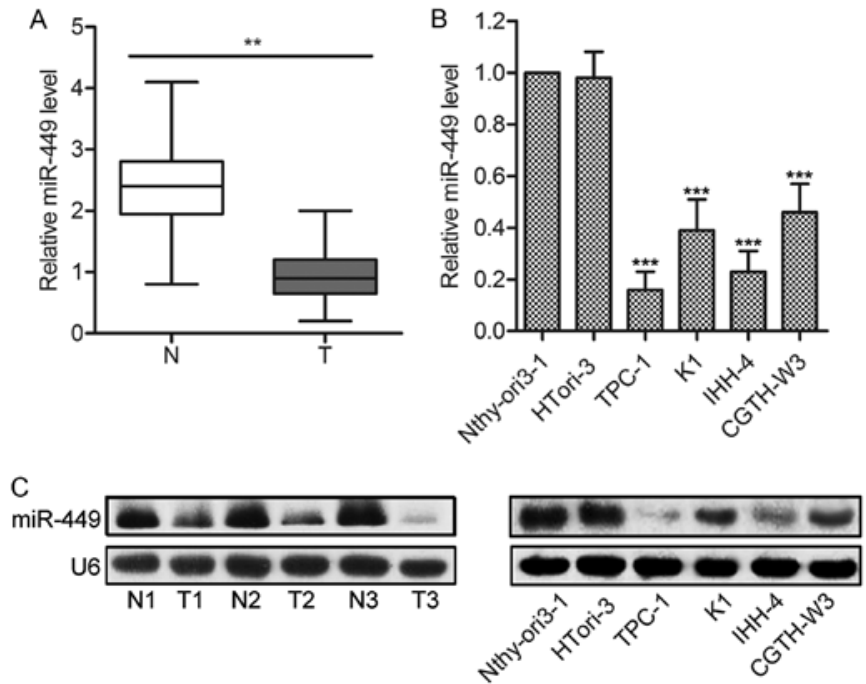

Figure 1. The levels of miR-449 expression are downregulated in PTC tissues and cell lines. (A) The relative expression of miR-449 in 25 human PTC tissues and adjacent non-tumor tissues was measured by qRT-PCR; (B) the expression of miR-449 in 2 TECs and 4 PTC cell lines; (C) the expression profile of miR-449 was measured using Northern blot assay. U6 was used as endogenous references. Data are represented as the mean \pm SD of three experiments. ${ }^{* *} \mathrm{P}<0.01$ vs. non-tumor tissues, ${ }^{* * *} \mathrm{P}<0.001$ vs. Nthy-ori3-1.

of each tumor was selected for western blotting for RET and key components of the Wnt/ $/$-catenin pathway and qRT-PCR analysis for miR-449.

Statistical analysis. All results were presented as mean \pm SD from a minimum of 3 replicates. Differences between groups were evaluated by the SPSS version 15.0 statistical software with Student's t-test when comparing only 2 groups or assessed by one-way ANOVA when $>2$ groups were compared. For the comparison of paired tissues, a paired Student's t-test was used to determine statistical significance. The relationship between RET and miR-449 expression was explored by Spearman's correlation. Differences were considered statistically significant at $\mathrm{P}<0.05$.

\section{Results}

The levels of miR-449 expression are downregulated in PTC tissues and cell lines. Firstly, the expression of miR-449 was measured in 20 fresh-frozen PTC specimens and adjacent normal tissues. The results of qPCR showed that the average expression levels of miR-449 were significantly lower in PTC tissues than in adjacent normal tissues $(\mathrm{P}<0.01$; Fig. $1 \mathrm{~A})$. Consistently, miR-449 expression was also decreased in PTC cell lines, such as TPC-1, CGTH-W3, K1 and IHH-4, compared with the non-cancerous human TECs $(\mathrm{P}<0.001$; Fig. 1B). Northern blot analysis was used to further confirm the decreased expression of miR-449 in PTC specimens and cell lines (Fig. 1C). Taken together, these results provide novel evidence for miR-449 downregulation in human PTC tissues and cell lines.

miR-449 overexpression suppresses the proliferation of PTC cells. To determine whether miR-449 regulates PTC 
A

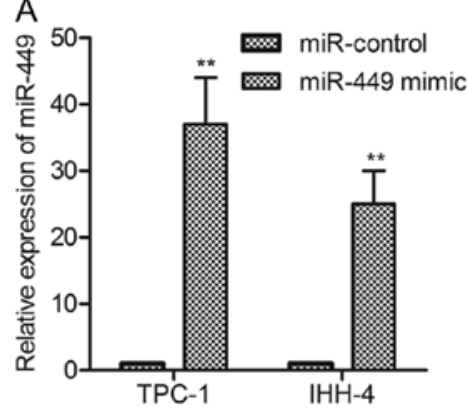

B

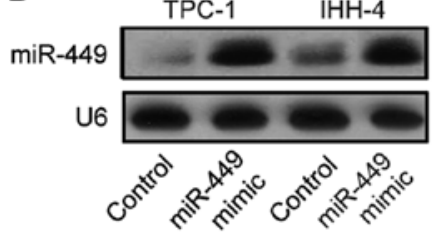

C

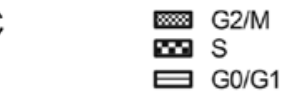

四/G1
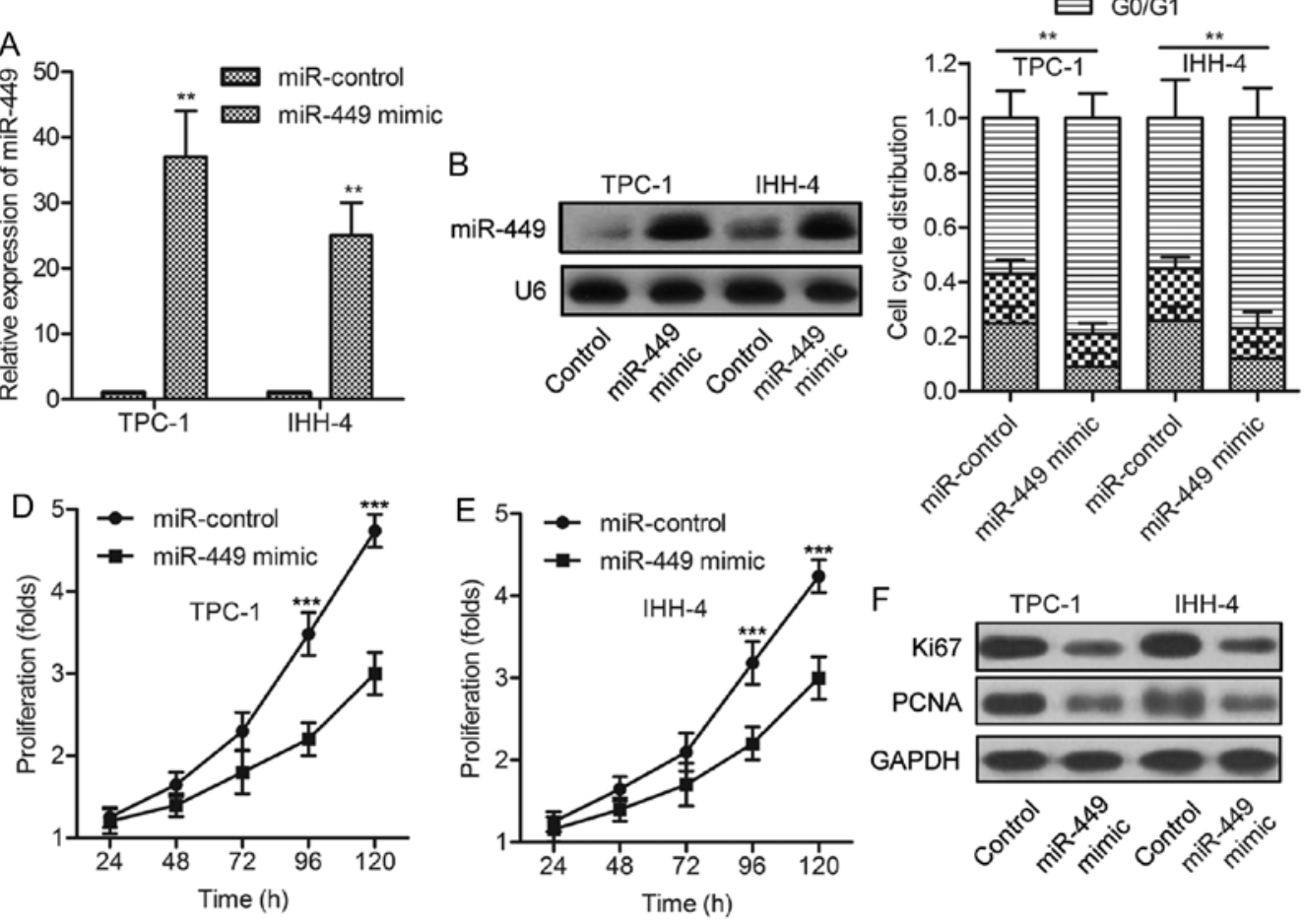

Figure 2. miR-449 overexpression suppresses the proliferation of PTC cells. (A) TPC-1 and IHH-4 cells were transfected with miR-499 mimic, followed by qPCR detection of miR-499 expression at $48 \mathrm{~h}$ after the treatment; (B) Northern blotting was used to confirm the effectiveness of miR-499 mimic transfection on TPC-1 and IHH-4 cells. (C) The distributions of G0/G1, S and G2/M phases were evaluated in TPC-1 and IHH-4 cells transfected with miR-499 mimic for $48 \mathrm{~h}$. (D,E) The proliferation of TPC-1 and IHH- 4 cells was determined at the indicated time-points (24-120 h) by MTT assays when adding miR-449 mimic. (F) The expression of Ki-76 and PCNA were detected by western blot assays in PTC cells when miR-449 was overexpressed for $48 \mathrm{~h}$. Data are presented as means $\pm \mathrm{SD}$. The statistically significant differences compared with the control are indicated: ${ }^{* *} \mathrm{P}<0.01 ;{ }^{* * *} \mathrm{P}<0.001$.

A

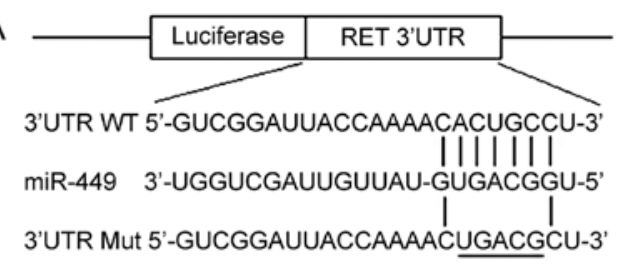

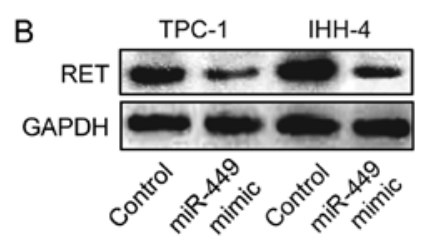

D

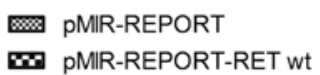

TPC-1

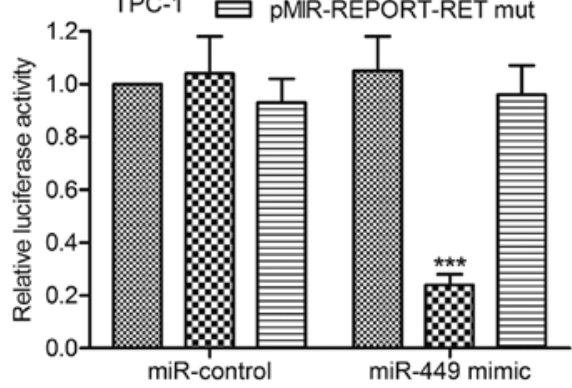

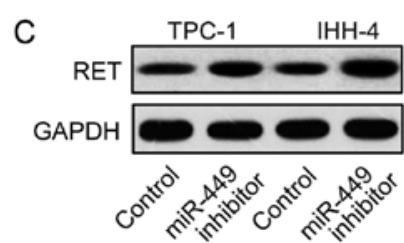

$\mathrm{E}$
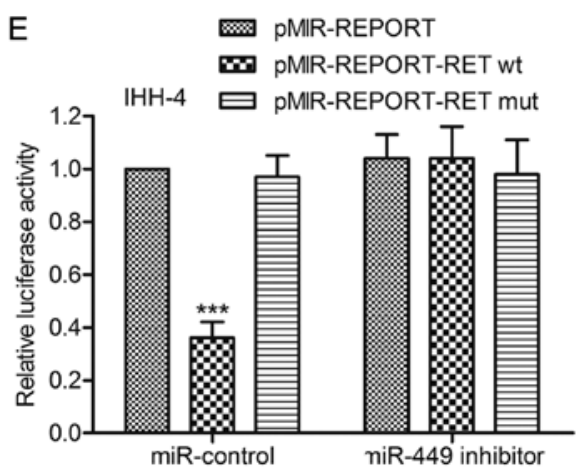

Figure 3. RET is a direct target of miR-449. (A) Target relationship between miR-449 and RET; RET expression was detected by immunoblot assays in TPC-1 and IHH-4 cells transfected with miR-449 mimic (B) or inhibitors (C) for $48 \mathrm{~h}$; TPC-1 cells were transfected with luciferase reporter vectors containing wildtype or mutant RET 3'-UTR. The expression levels of luciferase were determined $48 \mathrm{~h}$ after transfection of miR-449 mimic, or mimic control (D)/miR-449 inhibitor or inhibitor control (E). Data are presented as means \pm SD. The statistically significant differences compared with the control are indicated: ${ }^{* * * *} \mathrm{P}<0.001$. 

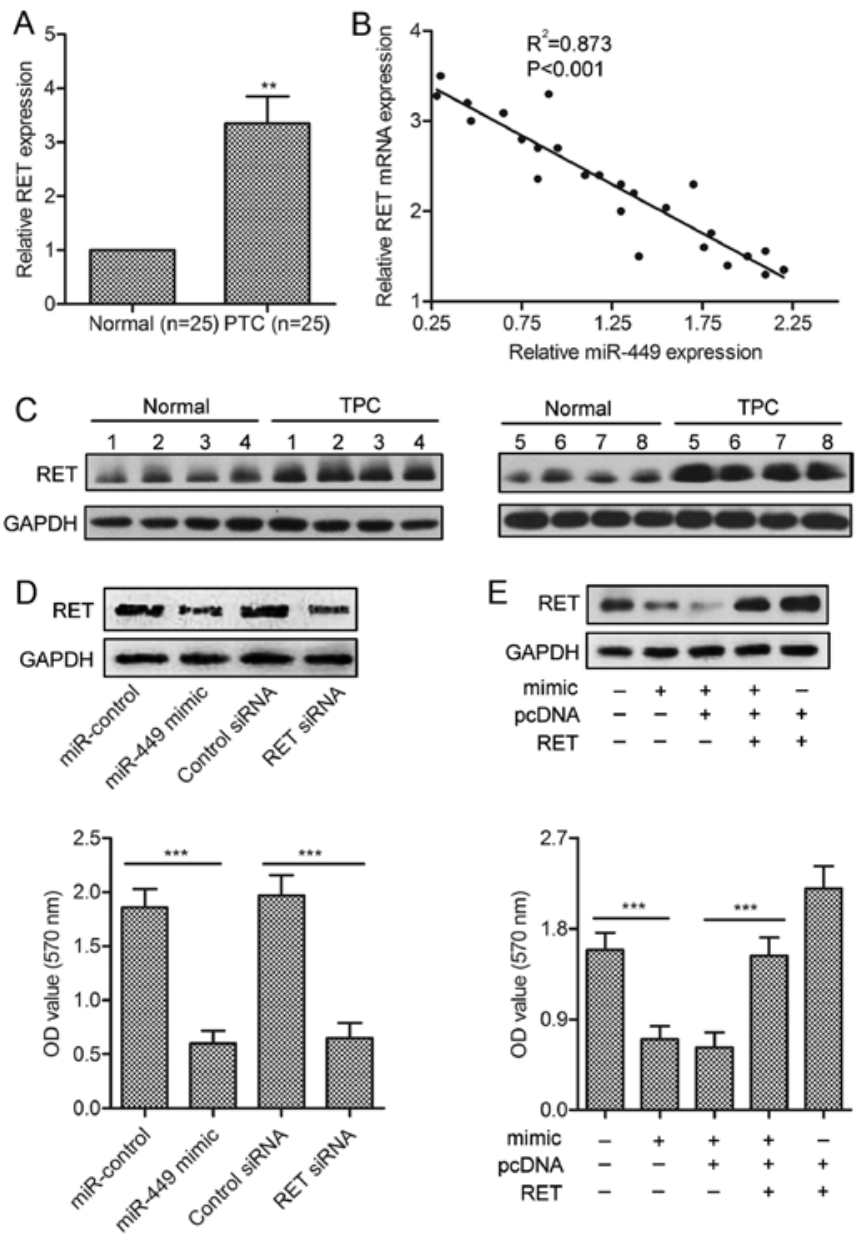

Figure 4. RET was involved in miR-449-induced growth promotion (A) Western blot analysis and (B) qRT-PCR analyses identified markedly increased RET protein expression in human PTC samples compared with paired normal tissues; (C) a statistically significant inverse correlation between miR-449 and RET mRNA levels in PTC specimens. (D) TPC-1 cells were infected with miR-449 mimic or transfected with RET siRNA. Cell growth rate were measured; (E) TPC-1 cells infected with miR-449 mimic were transfected with RET plasmid and MTT assay were then performed Data are presented as means \pm SD. The statistically significant differences compared with the control are indicated: ${ }^{* *} \mathrm{P}<0.01 ;{ }^{* * *} \mathrm{P}<0.001$.

cell growth, a synthetic activator specific for miR-449 was employed to suppress the expression of endogenous miR-449. The efficiency of this miR-449 activator was confirmed by qPCR assay and Northern blot analysis (Fig. 2A and B). FACS analysis indicated that miR-449 overexpression induced an accumulation in G0/G1 phase (Fig. 2C), implying the cell cycle arrest of PTC cells. The treatment of miR-449 mimic decreased the proliferation rates of TPC-1 and IHH-4 cells (Fig. 2D and E). Moreover, Ki-67, a mitosis-associated nuclear antigen in proliferating cells, and PCNA were consistently found to be underexpressed in TPC-1 and IHH- 4 cells treated with miR-449 mimic (Fig. 2F). The above data indicated that miR-449 overexpression inhibits the proliferation of PTC cells in vitro.

$R E T$ is a direct target of miR-449. To investigate the molecular mechanisms of miR-449 in PTC cell growth, putative miR-449 targets were predicted using TargetScan. The results revealed that RET was a potential target of miR-449.
The 3'-UTR of RET mRNA contains a complementary site for the seed region of miR-449 (Fig. 3A). To experimentally confirm RET as an authentic target of miR-449, the expression level of miR-449 was changed in TPC-1 and IHH-4 cells, followed by immunoblot analysis of RET levels. The data indicated that miR-449 overexpression caused the decline of RET expression, whereas miR-449 inhibition induced the restoration of RET (Fig. $3 \mathrm{~B}$ and C). To further verify the regulatory effect of miR-449 on RET, the plasmid pMIR-REPORT-RETwt or pMIR-REPORT-RETmut was transfected into TPC-1 cells together with miR-449 mimics. Luciferase expression levels by pMIR-REPORT-RETwt, but not pMIR-REPORT-RETmut, were found to be suppressed by synthetic miR-449 mimics (Fig. 3D). Consistently, miR-449 inhibitor rescued the reduction in the expression level of luciferase with wild-type RET 3'-UTR in U-87 MG glioma cells (Fig. 3E). Taken together, these results support the bioinformatics predictions indicating the RET 3'-UTR to be a direct target of miR-449.

RET is involved in miR-449-induced PTC cell growth promotion. To investigate whether RET is a functional target of miR-449, firstly, we measured the expression of RET in 25 pairs of clinical PTC samples using western blotting and qRT-PCR. Compared with paired normal tissues, PTC showed significantly higher RET expression $(\mathrm{P}<0.01$; Fig. 4A and B). We also analyzed the correlation between RET level and miR-449 expression in the same patients. As shown in Fig. 4C, a significant inverse correlation was observed $(\mathrm{P}<0.01$, $\mathrm{R}=0.873$ ). We further performed loss-of-function and gain-offunction studies by transfecting siRNA or RET plasmids in TPC-1 cells. As shown in Fig. 4D, siRNA against RET significantly inhibited cell growth, which is similar to those induced by miR-449. Besides, overexpression of RET could abolish the inhibitive effect of miR-449 (Fig. 4E).

Overexpression of miR-449 suppresses $\beta$-catenin nuclear translocation. To further explore the mechanism of G-17 on the growth of TPC-1 cells, the subcellular localization of $\beta$-catenin was measured. Cells in miR-control group displayed cytoplasmic and nuclear staining of $\beta$-catenin, whereas PGL group showed membrane $\beta$-catenin staining with minimal cytoplasmic or nuclear staining (Fig. 5A). To determine whether miR-449 could regulate $\mathrm{Wnt} / \beta$-catenin signaling, gain of-function analyses were performed by overexpressing $\beta$-catenin in TPC-1 cells transfected with miR-449 mimic (Fig. 5B). TPC-1 cells were transiently transfected with the Wnt signaling reporter TOPFlash or the negative control FOPFlash, along with miR-449 mimic or miR-control. The results indicated that TCF/LEF transcriptional activity was significantly decreased in miR-449-overexpressing cells, whereas this effect could be promoted by pcDNA- $\beta$-catenin (Fig. 5C). Flow cytometric analysis demonstrated that G0/G1 arrest was prevented in miR-449 overexpressing cells by pcDNA- $\beta$-catenin (Fig. 5D). Shown by MTT assays, overexpressing RET level could restore the proliferation rates of TPC-1 cells treated with miR-449 mimic (Fig. 5E). These data clearly suggested that miR-449 inhibited the nuclear translocation of $\beta$-catenin to inactivate the $\beta$-catenin pathway in TPC-1 cells. 
A

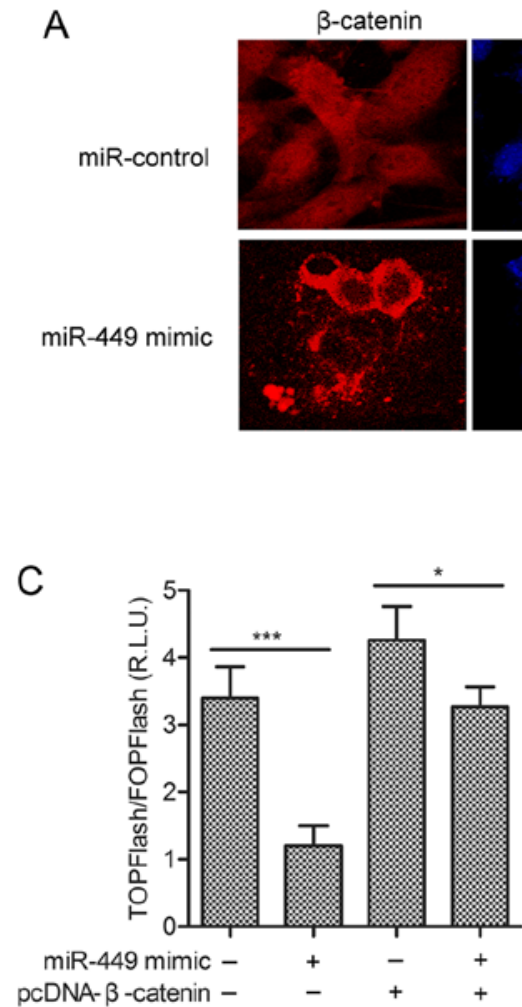

DAPI
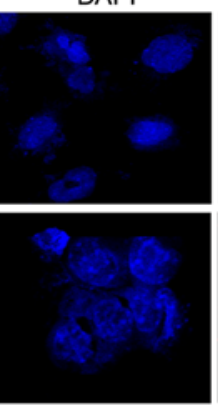

D
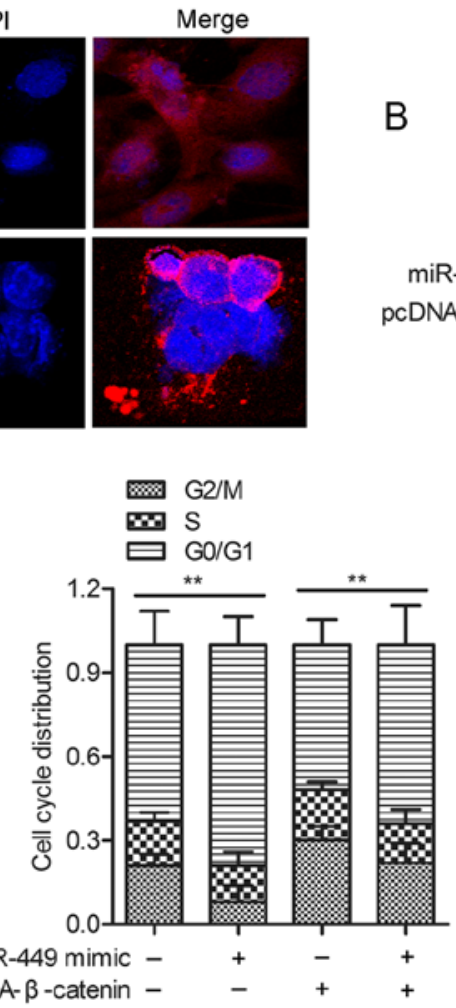

B
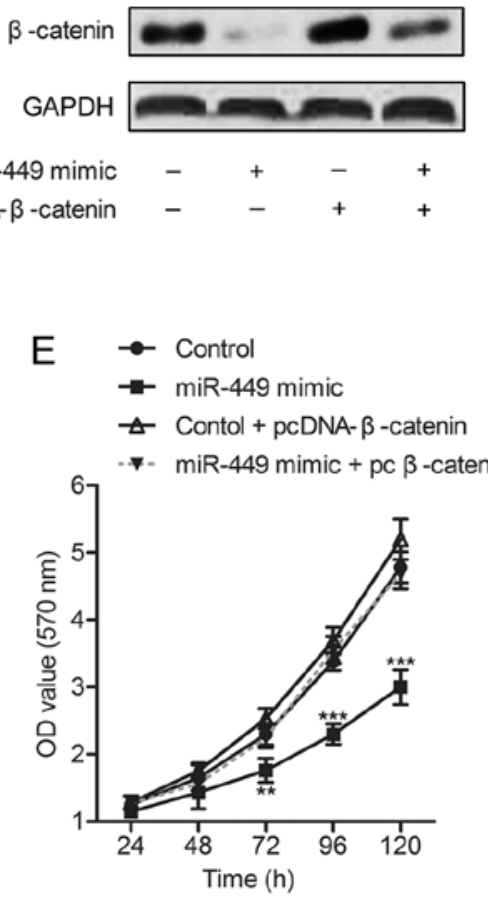

Figure 5. Overexpression of miR-449 suppresses the $\beta$-catenin nuclear translocation. (A) Immunofluorescence staining of $\beta$-catenin in TPC-1 cells were stained for $\beta$-catenin and counterstained with DAPI as indicated $(60 \mu \mathrm{m})$. (B) The expression of $\beta$-catenin in TPC-1 cells transfected with miR-449 and/or pcDNA- $\beta$-catenin was measured by western blot analysis. (C) Luciferase activity of TOPFlash/FOPFlash in miR-449-overexpressing cells; (D) the distributions of G0/G1, S and G2/M phases were evaluated in TPC-1 cells transfected with miR-499 mimic with/or pcDNA- $\beta$-catenin for 48 h; (E) the proliferation of TPC-1 cells was determined at the indicated time-points (24-120 h) by MTT assays when adding miR-449 mimic with/or pcDNA- $\beta$-catenin. Data are presented as means \pm SD. The statistically significant differences compared with the control are indicated: ${ }^{*} \mathrm{P}<0.05 ;{ }^{* *} \mathrm{P}<0.01 ;{ }^{* * *} \mathrm{P}<0.001$.

miR-449 reduces tumor growth and the expression of key downstream genes of $\beta$-catenin in xenograft models of PTC. To further investigate the inhibitive effect of miR-449 on tumor growth in vivo, miR-449-overexpressing and control TPC-1 cells were injected subcutaneously into the right scapula of each mouse $(n=5)$. The tumor growth of the miR-449-overexpressing tumors was significantly suppressed (Fig. 6A). The average tumor volume of miR-449-overexpressing tumors was lower compared with control tumors (Fig. 6B). The expression of Ki-67 and PCNA was significantly decreased compared with control group (Fig. 6C). qRT-PCR and western blot analyses revealed elevated miR-449 with decreased RET and $\beta$-catenin levels in miR-449-overexpressing tumors (Fig. 6D and E). Finally, we examined the effect of miR-449 mimic on the expression of c-Myc, cyclin D1, TCF-1 and LEF-1, which are key downstream genes of $\mathrm{Wnt} / \beta$-catenin signaling in tumor growth. As shown in Fig. 6F and 6G, the levels of these molecules were all decreased in TPC-1 and IHH-4 cells stably overexpressing miR-449 in vitro, and in miR-449-overexpressing tumors. These findings indicate that miR-449 inhibits tumor growth and the expression of Wnt/ $\beta$-catenin downstream genes in human PTC cells.

\section{Discussion}

The downregulation of miR-449 has been observed frequently in a variety of human malignancies, including lung (23), gastric cancers (11) and colon cancer stem cells (24). In accordance, the decreased expression of miR-449 was observed in human PTC tissues and cell lines in the present study. However, to date, the relationship between miR-449 and PTC is not fully understood. In this study, we demonstrated for the first time that miR-449 inhibits tumor growth of PTC by targeting a novel target, RET, which leads to the inactivation of $\beta$-catenin signaling.

Researchers have been convinced that aberrant miRNA expression is closely related to the changes of cell function. Bou Kheir et al (11) suggested that the deregulation of miR-449 not only leads to deregulated control of cell cycle proteins, but also of growth factors and their receptors. For instance, MCF-7 cells treated with miR-449 mimics were completely arrested at G1 phase. In gastric cancer cells, miR-449 induces apoptosis by inhibiting histone deacetylase, leading to p53 pathway activation and thus, the induction of apoptosis markers (11). In agreement with these reports, miR-449 overexpression in this study induced an accumulation in G0/G1 phase and decreased the proliferation of TPC-1 and IHH- 4 cells. Thus, our results suggest that miR-449 plays an inhibitive role in human PTC cell growth.

To date, several targets of miR-449 have been identified, such as AREG, CDK6 and HDAC1 $(25,26)$. On the basis of bioinformatics analysis, we further predicted another miR-449 target, RET. Reports have indicated that mutations in RET induce papillary carcinoma and familial medullary thyroid carcinoma in lung (27) and thyroid cancer (28). RET has been evidenced as an oncogene in a number of cancers, including 
A
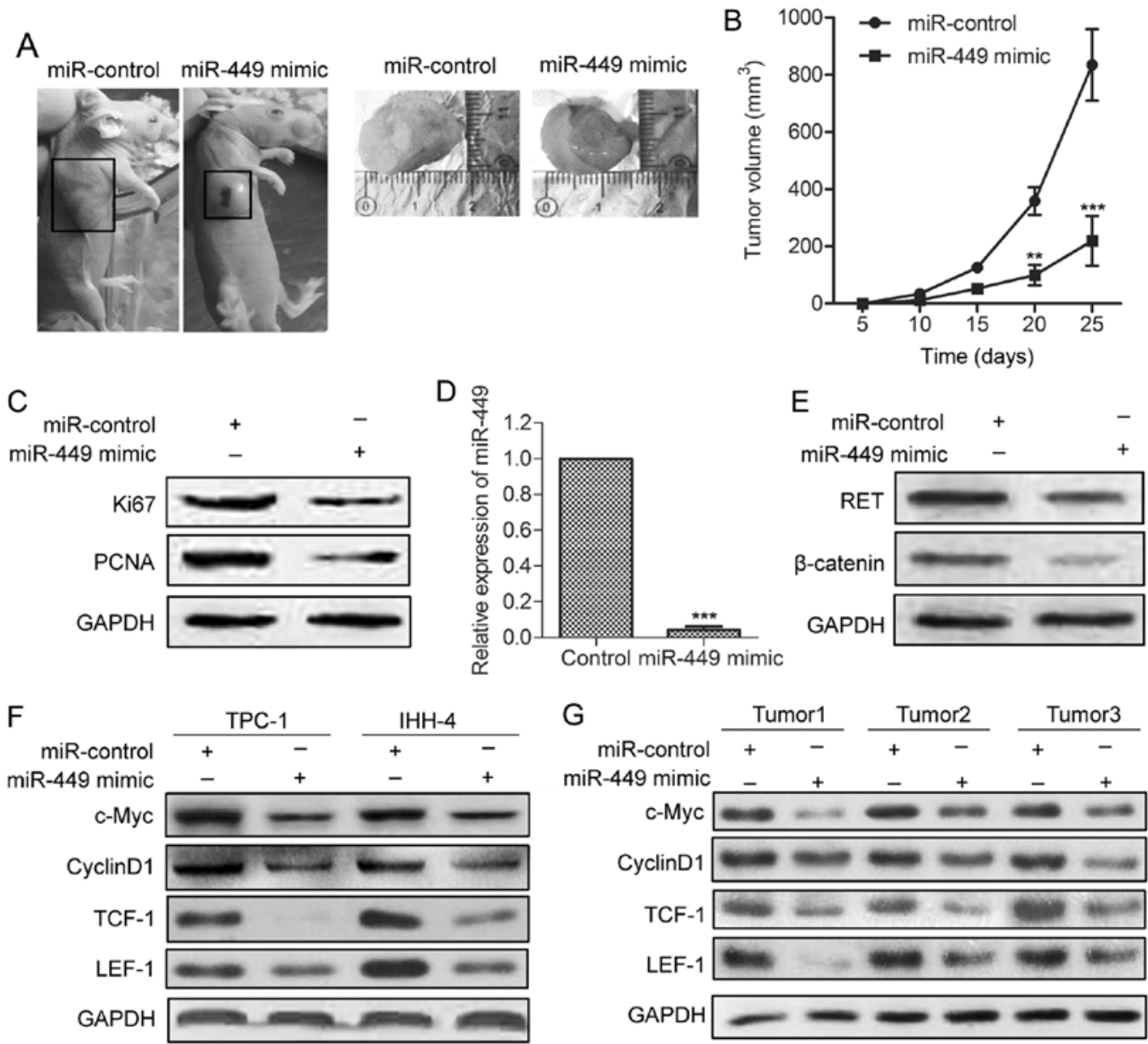

Figure 6. miR-449 reduces tumor growth and the expression of key downstream genes of $\beta$-catenin in xenograft models of PTC. (A) miR-449-300 overexpressing or control TPC-1 cells $\left(10^{6}\right)$ were injected subcutaneously into nude mice $(\mathrm{n}=5)$. At 25 days after implantation, the mice were sacrificed and the tumors were recovered; (B) volume of xenograft tumors. (C) The expressions of Ki-67 and PCNA were detected by western blotting. (D) Levels of miR-449 in xenograft tumor tissues as determined by qRT-PCR. (E) Western blot analysis of RET and $\beta$-catenin protein in miR-449-overexpressing and control xenograft tumor tissues. Expression of the c-Myc, cyclin D1, TCF-1 and LEF-1 genes in TPC-1 and IHH-4 cells stably overexpressing miR-449 (F), and in xenograft tumor tissues derived from miR-449-overexpressing and control TPC-1 cells (G). Tumors 1, 2 and 3 were obtained from 3 different mice. Data are presented as means \pm SD. The statistically significant differences compared with the control are indicated: ${ }^{* * *} \mathrm{P}<0.001$

head and neck squamous cell carcinoma (29), thyroid (30) and lung cancer (31). From the aspect mentioned above, targeting hNUDC with miR-449 may offer a novel strategy to prevent the oncogenic effect of RET in PTC. Our present experimental results confirmed that RET is a functional target of miR-449 in PTC cells. There are several pieces of evidence to support this. Firstly, confirmed by luciferase-reporter gene assays, miR-449 overexpression significantly downregulated RET by directly targeting the 3'-UTR of RET mRNA. This effect was largely eliminated when sites in the RET 3'-UTR targeted by miR-449 were mutated. Also, the expression of RET was significantly decreased in miR-449-overexpressing cells. Moreover, a significant inverse correlation was observed between RET and miR-449 expression in patients. We further found that the knockdown of RET inhibited cell growth similar to the phenotypes induced by miR-449 mimics, whereas RET overexpression could abolish the growth inhibitive effect of miR-449. These results strongly suggest that miR-449-reduced cell growth is partly mediated by the repression of RET expression.

Reports indicate that abnormal expression or localization of $\beta$-catenin has been found in different tumor types $(32,33)$, and loss of cell-cell adhesion mediated by $\beta$-catenin has been implicated in anchorage-independent cell growth (19). The nuclear localization of $\beta$-catenin may be an important marker of tumor progression or advanced disease in human medullary thyroid carcinoma. According to the report by Gujral et al (19), through RET-mediated tyrosine phosphorylation, $\beta$-catenin escapes cytosolic downregulation by the adenomatous polyposis coli/Axin/glycogen synthase kinase- 3 complex and accumulates in the nucleus, where it can stimulate $\beta$-cateninspecific transcriptional programs in a RET-dependent fashion. Their research evidenced that RET-induced activation of the $\beta$-catenin pathway may contribute to cell proliferation and tumorigenesis in thyroid carcinoma. Consistent with that report, our results demonstrate that miR-449-mediated downregulation of RET leads to inactivation of Wnt/ $\beta$-catenin signaling in PTC cells. First, miR-449 overexpression inhibited $\beta$-catenin accumulation and nuclear translocation. Second, miR-449 overexpression increased TCF/LEF transcriptional activity, and this effect was supported by the observation that overexpression of $\beta$-catenin prevented miR-449-reduced PTC viability. Moreover, miR-449 overexpression was found to enhance the expression of several $\beta$-catenin downstream genes 
in human PTC patients and cells. These results indicated that miR-449 inhibited the nuclear translocation of $\beta$-catenin to inactivate the Wnt pathway in TPC-1 cells.

Upregulation of $\beta$-catenin occurs in various cancers, namely hepatocellular carcinoma (34), prostate cancer (35) and cervical carcinoma (36). Increased free $\beta$-catenin pools have been observed in thyroid carcinomas secondary to reduced E-cadherin expression (19). Elevated levels of $\beta$-catenin were also reported in human PTC cells, and it has been suggested as a key molecule implicated in tumorigenesis in PTC (8). In medullary thyroid carcinoma cells, RET induces $\beta$-cateninmediated transcription, cell proliferation and transformation in vitro and $\beta$-catenin nuclear localization and the resultant RET-mediated $\beta$-catenin signaling appears to be a key secondary event in tumor growth and spreading in vivo. Our findings in this study demonstrate a key role of miR-449 for $\beta$-catenin activation in human PTC cells. Thus, miR-449 overexpression is a new mechanism that inactivates $\beta$-catenin in human PTC via targeting RET.

In conclusion, this study demonstrated that miR-449 was generally downregulated in both primary carcinoma and PTC cell lines. Overexpression of miR-218 reduced proliferation of PTC cells and reduced tumor growth of PTC cells in vivo. We also showed that RET was directly involved in the regulation of miR-218 during PTC development, possibly through $\beta$-catenin signaling pathway. Thus, the present study suggests that miR-449 may be a potential target for future prevention and treatment of human PTC.

\section{Acknowledgements}

The present study was funded by the Science and Technology Plan Project of Social Development Plans for Public Relations of Shaanxi Province, China (nos. 2012SF2-13 and 2015SF068).

\section{References}

1. Powell DJ Jr, Russell J, Nibu K, Li G, Rhee E, Liao M, Goldstein M, Keane WM, Santoro M, Fusco A, et al: The RET/PTC3 oncogene: Metastatic solid-type papillary carcinomas in murine thyroids. Cancer Res 58: 5523-5528, 1998.

2. Nikiforova MN, Kimura ET, Gandhi M, Biddinger PW, Knauf JA, Basolo F, Zhu Z, Giannini R, Salvatore G, Fusco A, et al: BRAF mutations in thyroid tumors are restricted to papillary carcinomas and anaplastic or poorly differentiated carcinomas arising from papillary carcinomas. J Clin Endocrinol Metab 88: 5399-5404, 2003.

3. Hong DS, Cabanillas ME, Wheler J, Naing A, Tsimberidou AM, Ye L, Busaidy NL, Waguespack SG, Hernandez M, El Naggar AK, et al: Inhibition of the Ras/Raf/MEK/ERK and RET kinase pathways with the combination of the multikinase inhibitor sorafenib and the farnesyltransferase inhibitor tipifarnib in medullary and differentiated thyroid malignancies. J Clin Endocrinol Metab 96: 997-1005, 2011.

4. Nikiforov YE and Nikiforova MN: Molecular genetics and diagnosis of thyroid cancer. Nat Rev Endocrinol 7: 569-580, 2011.

5. Yu H, Lu Y, Li Z and Wang Q: microRNA-133: Expression, function and therapeutic potential in muscle diseases and cancer. Curr Drug Targets 15: 817-828, 2014.

6. Zhi F, Wang Q, Deng D, Shao N, Wang R, Xue L, Wang S, Xia X and Yang Y: MiR-181b-5p downregulates NOVA1 to suppress proliferation, migration and invasion and promote apoptosis in astrocytoma. PLoS One 9: e109124, 2014.

7. Croce CM: Causes and consequences of microRNA dysregulation in cancer. Nat Rev Genet 10: 704-714, 2009.
8. Zhang X, Li M, Zuo K, Li D, Ye M, Ding L, Cai H, Fu D, Fan Y and Lv Z: Upregulated miR-155 in papillary thyroid carcinoma promotes tumor growth by targeting APC and activating Wnt $/ \beta$-catenin signaling. J Clin Endocrinol Metab 98: E1305-E1313, 2013.

9. Brest P, Lassalle S, Hofman V, Bordone O, Gavric Tanga V, Bonnetaud C, Moreilhon C, Rios G, Santini J, Barbry P, et al: MiR-129-5p is required for histone deacetylase inhibitor-induced cell death in thyroid cancer cells. Endocr Relat Cancer 18: 711-719, 2011.

10. Geraldo MV, Fuziwara CS, Friguglieti CU, Costa RB, Kulcsar MA, Yamashita AS and Kimura ET: MicroRNAs miR-146-5p and let-7f as prognostic tools for aggressive papillary thyroid carcinoma: A case report. Arq Bras Endocrinol Metabol 56: 552-557, 2012.

11. Bou Kheir T, Futoma-Kazmierczak E, Jacobsen A, Krogh A, Bardram L, Hother C, Grønbæk K, Federspiel B, Lund AH and Friis-Hansen L: miR-449 inhibits cell proliferation and is downregulated in gastric cancer. Mol Cancer 10: 1, 2011.

12. Trupp M, Arenas E, Fainzilber M, Nilsson AS, Sieber BA, Grigoriou M, Kilkenny C, Salazar-Grueso E, Pachnis V, Arumäe U, et al: Functional receptor for GDNF encoded by the c-ret proto-oncogene. Nature 381: 785-789, 1996.

13. Gujral TS, van Veelen W, Richardson DS, Myers SM, Meens JA, Acton DS, Duñach M, Elliott BE, Höppener JW and Mulligan LM: A novel RET kinase-beta-catenin signaling pathway contributes to tumorigenesis in thyroid carcinoma. Cancer Res 68: 1338-1346, 2008.

14. Marx SJ: Molecular genetics of multiple endocrine neoplasia types 1 and 2. Nat Rev Cancer 5: 367-375, 2005.

15. Arighi E, Borrello MG and Sariola H: RET tyrosine kinase signaling in development and cancer. Cytokine Growth Factor Rev 16: 441-467, 2005.

16. Hoppler S and Kavanagh CL: Wnt signalling: Variety at the core. J Cell Sci 120: 385-393, 2007.

17. Moon RT, Kohn AD, De Ferrari GV and Kaykas A: WNT and beta-catenin signalling: Diseases and therapies. Nat Rev Genet 5: 691-701, 2004

18. Garcia-Rostan G, Camp RL, Herrero A, Carcangiu ML, Rimm DL and Tallini G: Beta-catenin dysregulation in thyroid neoplasms: Down-regulation, aberrant nuclear expression, and CTNNB1 exon 3 mutations are markers for aggressive tumor phenotypes and poor prognosis. Am J Pathol 158: 987-996, 2001.

19. Gujral TS, van Veelen W, Richardson DS, Myers SM, Meens JA, Acton DS, Duñach M, Elliott BE, Höppener JW and Mulligan LM: A novel RET kinase- $\beta$-catenin signaling pathway contributes to tumorigenesis in thyroid carcinoma. Cancer Res 68: 1338-1346, 2008

20. Liu J, Ma L, Li C, Zhang Z, Yang G and Zhang W: Tumortargeting TRAIL expression mediated by miRNA response elements suppressed growth of uveal melanoma cells. Mol Oncol 7: 1043-1055, 2013

21. Ma L, Liu J, Liu L, Duan G, Wang Q, Xu Y, Xia F, Shan J, Shen J, Yang Z, et al: Overexpression of the transcription factor MEF2D in hepatocellular carcinoma sustains malignant character by suppressing G2-M transition genes. Cancer Res 74: 1452-1462, 2014.

22. Gilles C, Polette M, Mestdagt M, Nawrocki-Raby B, Ruggeri P, Birembaut $\mathrm{P}$ and Foidart JM: Transactivation of vimentin by $\beta$-catenin in human breast cancer cells. Cancer Res 63: 2658-2664, 2003.

23. Luo W, Huang B, Li Z, Li H, Sun L, Zhang Q, Qiu X and Wang E: MicroRNA-449a is downregulated in non-small cell lung cancer and inhibits migration and invasion by targeting c-Met. PLoS One 8: e64759, 2013.

24. Fang Y, Gu X, Li Z, Xiang J and Chen Z: miR-449b inhibits the proliferation of SW1116 colon cancer stem cells through downregulation of CCND1 and E2F3 expression. Oncol Rep 30: 399-406, 2013

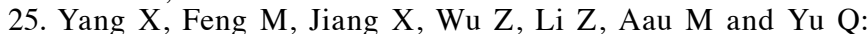
miR-449a and miR-449b are direct transcriptional targets of $\mathrm{E} 2 \mathrm{~F} 1$ and negatively regulate pRb-E2F1 activity through a feedback loop by targeting CDK6 and CDC25A. Genes Dev 23: 2388-2393, 2009

26. Buurman R, Gürlevik E, Schäffer V, Eilers M, Sandbothe M, Kreipe H, Wilkens L, Schlegelberger B, Kühnel F and Skawran B: Histone deacetylases activate hepatocyte growth factor signaling by repressing microRNA-449 in hepatocellular carcinoma cells. Gastroenterology 143: 811-820.e15, 2012. 
27. Takeuchi K, Soda M, Togashi Y, Suzuki R, Sakata S, Hatano S, Asaka R, Hamanaka W, Ninomiya $\mathrm{H}$, Uehara $\mathrm{H}$, et al: RET, ROS1 and ALK fusions in lung cancer. Nat Med 18: 378-381, 2012.

28. Melillo RM, Castellone MD, Guarino V, De Falco V, Cirafici AM, Salvatore G, Caiazzo F, Basolo F, Giannini R, Kruhoffer M, et al: The RET/PTC-RAS-BRAF linear signaling cascade mediates the motile and mitogenic phenotype of thyroid cancer cells. J Clin Invest 126: 1603, 2016.

29. Lin C, Lu W, Ren Z, Tang Y, Zhang C, Yang R, Chen Y, Cao W, Wang L, Wang X, et al: Elevated RET expression enhances EGFR activation and mediates EGFR inhibitor resistance in head and neck squamous cell carcinoma. Cancer Lett 377: 1-10, 2016.

30. Bano G and Hodgson S: Diagnosis and management of hereditary thyroid cancer. Recent Results Cancer Res 205: 29-44, 2016

31. Drilon A, Bergagnini I, Delasos L, Sabari J, Woo KM, Plodkowski A, Wang L, Hellmann MD, Joubert P, Sima CS, et al: Clinical outcomes with pemetrexed-based systemic therapies in RET-rearranged lung cancers. Ann Oncol 27: 1286-1291, 2016.

32. Bauman TM, Vezina CM, Ricke EA, Halberg RB, Huang W, Peterson RE and Ricke WA: Expression and colocalization of $\beta$-catenin and lymphoid enhancing factor-1 in prostate cancer progression. Hum Pathol 51: 124-133, 2016.
33. Lan L, Deng W, Chen H, Huo L, Deng L, Zhang G and Luo Y: Nuclear translocation of $\beta$-catenin represses membrane localization of NIS in human thyroid cancer cells. Zhonghua Yi Xue Za Zhi 96: 891-896, 2016 (In Chinese).

34. Li T, Zhong J, Dong X, Xiu P, Wang F, Wei H, Wang X, Xu Z, Liu F, Sun X, et al: Meloxicam suppresses hepatocellular carcinoma cell proliferation and migration by targeting COX-2/ PGE2-regulated activation of the $\beta$-catenin signaling pathway. Oncol Rep 35: 3614-3622, 2016.

35. Lombardi AP, Pisolato R, Vicente CM, Lazari MF, Lucas TF and Porto CS: Estrogen receptor beta $(\mathrm{ER} \beta)$ mediates expression of $\beta$-catenin and proliferation in prostate cancer cell line PC-3. Mol Cell Endocrinol 430: 12-24, 2016.

36. Chen Q, Zheng PS and Yang WT: EZH2-mediated repression of GSK-3 $\beta$ and TP53 promotes Wnt $/ \beta$-catenin signaling-dependent cell expansion in cervical carcinoma. Oncotarget: Apr 15, 2016. (Epub ahead of print). doi: 10.18632/oncotarget.8741. 